neuropsychiatric attacks that may be precipitated by drugs, especially barbiturates, during which large amounts of the colourless porphyrin precursors, porphobilinogen (PBG) and o-aminolaevulic acid (ALA), are excreted.

The first reaction in the biosynthesis of haem is the formation of ALA, and this is catalysed by the mitochondrial enzyme $\delta$-aminolaevulate synthetase (ALA-S). This reaction limits the rate at which hepatic haem is synthesized." Alterations in the activity of ALA-S in the liver cell are probably due to induction or inhibition of its synthesis. The enzyme is induced by a wide variety of compounds, including a number of drugs and steroids. Haem inhibits the induction of ALA-S, and so regulates its own synthesis. ${ }^{6} 7$ In 1965 D. P. Tschudy and his co-workers reported an increase in the activity of ALA-S in the liver of a patient who had died from acute intermittent porphyria. ${ }^{8}$ This finding supported the view that acute intermittent porphyria is an "overproduction" disease in which excessive amounts of porphyrin precursors are produced owing to an inherited defect in the regulation of ALA-S synthesis. ${ }^{9}$ An increase in the activity of liver ALA-S has now been found in all the inherited hepatic porphyrias. ${ }^{10-12}$ If overproduction of ALA in the liver were the only lesion in haem biosynthesis in these conditions, one would expect the pattern of porphyrin excretion to be the same in each disease and to resemble that produced by administering a dose of ALA to a normal person. ${ }^{13}$ In fact this is not so. The different forms of hepatic porphyria are characterized by different patterns of porphyrin excretion. ${ }^{3}$ It has recently been suggested that, since it is unlikely that two separate genetic lesions are present in each type of hepatic porphyria-one leading to overproduction of ALA and one determining the consequent excretion pattern-the primary defect is probably an inherited partial block in the biosynthesis of haem at a different, characteristic step for each disease. ${ }^{12}$ The increase in ALA-S would then come about through the normal control mechanism operating to increase the synthesis of intermediates to maintain hepatic levels of haem in the face of such a block.

H. S. Marver and his co-workers have reported evidence for a partial block in the synthesis of haem in acute intermittent porphyria. " They found that conversion of porphobilinogen to porphyrin was less than $50 \%$ of normal in the liver of three patients with acute intermittent porphyria, whereas it was normal in variegate porphyria. In both conditions the ALA-S activity was increased. A block in the conversion of porphobilinogen to uroporphyrinogen explains the observed excretion of large amounts of porphobilinogen and ALA, but not porphyrins, in acute intermittent porphyria. However, it conflicts with an earlier report of a nearly twofold increase in the conversion of porphobilinogen to porphyrins in one patient with this disease. ${ }^{15}$

Prevention of acute attacks by ensuring that, so far as possible, patients avoid known precipitating factors is of the utmost importance in the management of the inherited hepatic porphyrias. ${ }^{12}$ Many of the drugs, such as barbiturates, that provoke acute attacks induce hepatic ALA-S ${ }^{6}$ and are metabolized in the liver by haem-containing microsomal enzyme systems. ${ }^{16}$

Additional evidence that induction of ALA-S is involved in the mechanism of the acute attack comes from reports that steroid inducers of ALA-S are present in the urine ${ }^{17}$ and unidentified inducing substances in the plasma. ${ }^{18}$ Moreover, carbohydrate loading, which inhibits the formation of ALA-S, benefits these patients. ${ }^{1}$ On the other hand there is no consistent relationship in acute intermittent porphyria between the excretion of porphobilinogen and ALA and the onset of acute attacks, ${ }^{19}$ though correlation is better in variegate porphyria and hereditary coproporphyria.

If the primary lesions in the inherited hepatic porphyrias lie in the pathway of porphyrin synthesis, a causal relationship should exist between the clinical features of the acute attack, all of which probably have a neurological basis, and the disturbance of haem biosynthesis. But the cause of the neurological lesions remains obscure. The discovery of a connexion between the neurological and the biochemical abnormalities remains an outstanding problem.

${ }^{1}$ Goldberg, A., Proceedings of the Royal Society of Medicine, 1968, 61, 193.

2 Taddeini, L., and Watson, C. J., Seminars in Haematology, 1968, 5, 335.

3 Eales, L., Levey, M. J., and Sweeney, G. D., South African Medical fournal, 1966, 40, 63.

4 International Conference on Porphyrin Metabolism and the Porphyrias, Cape Town, 2-6 December 1970. Proceedings to be published, South African Journal of Laboratory and Clinical Medicine.

s Granick, S., and Urata, G., fournal of Biological Chemistry, 1963, 238, 821. Granick, S., fournal of Biological Chemistry, 1966, 241, 1359.

Marver, H. S., Schmid, R., and Schützel, H., Biochemical and Biophysical Research Communications, 1968, 33, 969.

8 Tschudy, D. P., Perlroth, M. G., Marver, H. S., Collins, A., Hunter, G., and Rechcigl, M., Proceedings of the National Academy of Science of the United States of America, 1965, 53,841.

$\checkmark$ Watson, C. J., Runge, W., Taddeini, L., Bossenmaier, I., and Cardinal, R. A., Proceedings of the National Academy of Science of the United R. A., Proceedings of the National

10 Dowdle, E. B., Mustard, P., and Eales, L., South African Medical Fournal, 1967, 41, 1093.

1 Masuya, T., Acta haematologica faponica, 1969, 32, 519.

Kaufman, L., and Marver, H. S., New England fournal of Medicine, 1970, 238, 954.

Dowdle, E. B., Mustard, P., Spong, N., and Eales, L., Clinical Science, $1968,34,233$

Strand, L. J., Felsher, B. J., Redeker, A. G., and Marver, H. S., Proceedings of the National Academy of Science of the United States of America, 1970, 67, 1315 .

15 Nakao, K., Wada, O., Kitamura, T., Uomo, K., Urata, G., Nature, $1966,210,839$.

${ }^{16}$ Marver, H. S., and Schmid, R., Gastroenterology, 1968, 55, 282.

17 Goldberg, A., et al., Lancet, 1969, 1, 115.

is Kappas, A., Song, C. S., Sassa, S., Levere, R. D., and Granick, S., Proceedings of the National Academy of Science of the United States of Proceedings of the National

${ }^{19}$ Ackner, B., Cooper, J. E., Gray, C. H., Kelly, K., and Nicholson, D. C., Lancet, 1961, 1, 1256.

\section{Human Growth Hormone}

For some years growth hormone isolated from human pituitary glands obtained at necropsy has been given successfully in Great Britain to promote growth in certain types of dwarfed children. ${ }^{1}$ Since growth hormone obtained from beef or sheep pituitaries is ineffective in these cases, the Medical Research Council sponsors the collection of human pituitaries post mortem by pathologists throughout the country so that small amounts of the human hormone can be made available for clinical trials under controlled conditions. Human growth hormone is a protein composed of nearly 200 amino-acid residues, with a molecule about three times as large as that of insulin. The publication in 1966 of the complete amino-acid sequence of human growth hormone represented a notable advance in our knowledge about this protein. ${ }^{2}$

In addition to growth-promoting activity highly purified preparations of human growth hormone also possess prolactin activity. ${ }^{34}$ This is not the case in several other mammalian species (including pig and ox), in which growth hormone and prolactin activities are found in distinct and separable protein hormones. ${ }^{5}$ Attempts to remove the prolactin activity from human growth hormone have not been successful, and therefore it has been assumed that both hormone activities are present in the same protein molecule.

The newest development in this field is the synthesis of a protein with the amino-acid sequence previously reported 
for human growth hormone. ${ }^{6}$ The synthesis was performed with the aid of an automated instrument which links aminoacid derivatives one by one to the first amino-acid attached to a solid resin support. ${ }^{7}$ The individual steps were not completely efficient, and further treatments were necessary to remove the solid support and introduce two disulphide linkages. This resulted in a low yield of protein with chemical properties similar to the naturally occurring hormone. The biological activity of the product was low, being approximately $10 \%$ of the growth-promoting activity and $5 \%$ of the prolactin activity of growth hormone isolated from human pituitaries. Nevertheless these studies provide additional evidence that the same hormone possesses both growth-promoting and prolactin activities.

Synthetic human growth hormone prepared by this method is not of satisfactory purity or of sufficient yield to be of use for the treatment of patients. The potency of highly purified naturally occurring human growth hormone is about $2 \mathrm{IU} / \mathrm{mg}$. Preparations of about half this potency are used in Britain for the treatment of dwarfed children in doses varying from 10 IU to 60 IU per week. ${ }^{1}$ Efficient extraction procedures yield approximately 9 IU from a single pituitary gland, ${ }^{8}$ which provides considerably more growth-promoting activity than was obtained by the laborious and very expensive synthetic method. It can be expected, therefore, that the requirement for growth hormone prepared from human pituitaries will continue for a long time to come.

1 Tanner, J. M., and Whitehouse, R. H., British Medical fournal, 1967, 2,69 .

Li, C. H., Liu, W. K., and Dixon, J. S., fournal of the American Chemical Society, 1966, 88, 2050.

3 Ferguson, K. A., and Wallace, A. L. C., Nature, 1961, 190, 632.

- Chadwick, A., Folley, S. J., and Gemzell, C. A., Lancet, 1961, 2, 241.

syons, W. R., and Dixon, J. S., in The Pituitary Gland, ed. G. W Harris and B. T. Donovan, Vol. 1, p. 527, London. Butterworths, 1966.

- Li, C. H., and Yamashiro, D., fournal of the American Chemical Society, 1970, 92, 7608

' Merrifield, R. B., Stewart, J. M., and Jernberg, N., Analytical Chemistry, 1966, 38, 1905.

sills, J. B., Ashworth, R. B., Wilhelmi, A. E., and Hartree, A. S., fournal of Clinical Endocrinology and Metabolism, 1969, 29, 1456.

\section{Depressive Illness in Children}

Depressive illness in children, long considered to be rare, is now being diagnosed more frequently. Possibly the increasing use of antidepressant drugs is focusing attention on a diagnosis which, in childhood, is by no means universally accepted or clearly defined. One of the difficulties is that the presentation of the disorder differs in adult life and childhood and, indeed, is said to vary widely in the latter. Even so, such discrepancies should be acceptable, for the signs and symptoms of many disorders change considerably with age. As John Apley' has pointed out, "childhood can be neither understood nor taught by extrapolating back from adults".

Twenty-five years ago "anaclitic depression" was described in infants reared away from their mothers. ${ }^{2}$ The infants became miserable, expressionless, and withdrawn-some of the hallmarks of depression. In the few years after infancy disturbances which might be attributed to depression are surprisingly unusual, though every general practitioner sees children who continue to be miserable and moody, perhaps after bereavement or in a home atmosphere of parental hostility, rejection, or mental illness. Later in childhood depressive illness can probably first show itself in the guise of "school refusal". Against a background of distorted family relationships this often presents with a bodily symptom, such as pain, followed by refusal to attend school and a loss of appetite and weight.

The criteria for diagnosing depression in children are still not agreed or established, though different reports include most of the following symptoms and signs: bodily complaints; poor appetite and loss of weight; lack of energy; irritability, misery, and excessive crying; sleep difficulties and perhaps self-deprecation. The diagnosis has become even more difficult because such terms as "depression equivalents" and "masked depression" have been introduced. ${ }^{3}$ This is a phase strikingly reminiscent of epilepsy, with its "epileptic equivalents" and "masked epilepsy". In both disorders one is tempted to suggest that not the disease but the doctor is masked. Among equivalents and masked symptoms in depressive illness are included boredom, fatigue, and lack of concentration ${ }^{4}$ and some psychosomatic complaints. In one group of 25 children presenting with severe headache 10 were diagnosed as depressive, ${ }^{5}$ while E A. Frommer 6 has emphasized the frequency of abdominal pain and Frommer and D. Cottom ${ }^{7}$ consider that an unspecified proportion of "little bellyachers" suffer from depression.

In adults an association between headache and depression is often accepted, ${ }^{9}$ but $\mathrm{W}$. Ling and his colleagues, pointing out that their cases were highly selective, conclude that in children "migraine headache per se cannot be considered a monosymptomatic manifestation of depression". When Apley's monograph ${ }^{8}$ is scrutinized in the light of what Frommer and Cottom say it seems clear that his little bellyachers were more likely to suffer from an anxiety state rather than from depression. Moreover, at present it does not seem justified to try to distinguish between the two conditions by treating the individual child with antidepressant drugs. Though considerable claims have been made for such drugs, ${ }^{6} 10$ some child psychiatrists have abandoned them and others deny that they have any place in treatment, even in true depression. ${ }^{11}$

Hence the place of antidepressant drugs in childhood depression is not established, though the indications may become clearer if diagnostic criteria become reliable. What should surely be accepted is that drugs are never a substitute for management of the child in the family in a situation, characterized ${ }^{12}$ by a reduction in responsiveness to external stimulation, which may reach deadlock. How much of this is to be carried out by family doctors and paediatricians, who see almost all the youngest cases at least, or by child or family psychiatrists, will continue to be argued. ${ }^{10}$ Skilled psychiatric help will clearly be advisable if depressive illness in a child is diagnosed or is seriously suspected.

1 Apley, J., Lancet, 1965, 2, 633-634.

2 Spitz, R. A., and Wolf, K. M., Psychoanalytic Study of the Child, 1946, $2,313$.

3 Poznanski, E., and Zrull, J. P., Archives of General Psychiatry, 1970, 23, 8

Toolan, J. M., Adolescence: Psychosocial Perspectives, eds. G. Caplan, oolan, J. M., Adolescence: Psychosocial Perspectives,

s Ling, W., Oftedal, G., and Weinberg, W., American fournal of Diseases of Children, 1970, 120, 122

- Frommer, E. A., Recent Developments in Affective Disorders, eds. A. Coppen and A. Walk, p. 117. London, Royal Medico-Psychological Association, 1968.

? Frommer, E. A., and Cottom, D., British Medical fournal, 1970, 4, 113.

8 Apley, J., The Child with Abdominal Pains, Oxford, Blackwell, 1959.

- Cochrane, A. L., Background to Migraine, London, Heinemann, 1969.

10 Willner, M. M., and Gordon, L. E., Clinical Pediatrics, 1969, 8. 193.

11 Chapman, A. H., The Physician's Guide to Managing Emotional Problems, p. 85, Philadelphia, Lippincott, 1969.

12 Davis, D. R., An Introduction to Psychopathology, 2nd edn. London, Oxford University Press, 1966. 